This is an Accepted Manuscript of a book chapter published by Routledge, in Christoph Demmerling and Dirk Schröder (eds.) Concepts in Thought, Action, and Emotion: New Essays, on Dec. 30, 2020, available online: https://www.taylorfrancis.com/books/concepts-thought-actionemotion-christoph-demmerling-dirk-schr\%C3\%B6der/e/10.4324/9780429455889?refId=e24532e2ac85-42ca-93df-ebff99c0a418.

\title{
The Explanatory Merits of Reasons-First Epistemology
}

\author{
Eva Schmidt
}

\section{Introduction}

Littlejohn (2017) has recently complained that, though many philosophers accept reasons-first epistemology, there haven't been any arguments presented in its support. To rectify this situation, I will here present an argument for the reasons-first view: It is superior to knowledge-first views in particular in that - unlike them - it can both explain the specific epistemic role of perception and account for the shape and extent of epistemic justification.

Ever since Williamson (2000) called into question the once widely accepted assumption that we need to understand knowledge in terms of justification and claimed instead that our evidence is what we know, that knowledge is not analyzable, and that anyway remembering, perceiving etc. are ways of knowing, the order of matters epistemological has been up in the air. One question this state of confusion gives rise to is, "Which epistemic phenomenon is fundamental, and can thus be taken to explain the others?" My discussion will address this question, focusing on a comparison of reasonsfirst epistemology with knowledge-first epistemology. I will argue that, rather than taking knowledge to be fundamental (with respect to justification and reasons), we should see epistemic reasons as fundamental (with respect to knowledge and justification).

Here is an example to illustrate the issue. One evening as he enters his sister Hiltrud's bedroom, Klaus hears that she is snoring and, for that reason, believes that she is sleeping. I assume that in this case Klaus's belief that Hiltrud is sleeping is justified; indeed, it is knowledge. The Williamsonian knowledge-first account of the epistemic standing of Klaus's belief is this: Perceiving that Hiltrud is snoring is a way of knowing that Hiltrud is snoring, since perception is a kind of knowledge. In virtue of this knowledge Klaus possesses the fact that Hiltrud is snoring as evidence that his sister is sleeping, he thereby has justification for his belief that she is sleeping, and the belief, since it is based on his auditory knowledge, is justified. By contrast, my preferred reasons-first account has it that Klaus's hearing that Hiltrud is snoring brings an epistemic reason for believing that she is sleeping 
(viz. that she is snoring) into his possession. Since Klaus believes that Hiltrud is sleeping in competent response to this reason, Klaus both knows and justifiably believes this. His hearing is not itself knowledge, though it provides justification for his belief that Hiltrud is snoring and is the source of his knowledge that she is snoring (Schmidt 2019).

Knowledge-first and reasons-first, as I understand them, are concerned with the explanatory order of central epistemic phenomena. According to knowledge-first, we can provide a deeper explanation of the possession of evidence or reasons and of justification by turning to knowledge. By contrast, according to reasons-first, we can only explain how agents know or justifiably believe something if we turn to the reasons they have, because the latter are fundamental to both epistemic standings.

Since the central concern of both views is explanatory fundamentality, the obvious way to argue for either one is by pointing to its explanatory merits in comparison to the competition. One can show that, say, "X-first" is better than "Y-first" if, on the assumption that X is explanatorily fundamental, the relevant phenomena can be better explained - or be better done justice to - than on the assumption that $\mathrm{Y}$ is explanatorily basic. This is exactly what I intend to do here. Reasons-first gives a better account than knowledge-first of the justification of our beliefs, including our most fundamental perceptual beliefs; in addition, it - unlike knowledge-first - does justice to the specific ways in which perception is epistemically significant. ${ }^{1}$

Here is how I proceed: In the next section, I highlight the epistemic roles of perception and certain features of epistemic justification. Next, I show that knowledge-first views which equate perception with a kind of knowledge (called "PIK") cannot satisfactorily account for either and that, while rejecting this equation helps, the resulting knowledge-first view (called "PINK") still has explanatory problems. I then present my own reasons-first view in more detail and argue that it explains the epistemic relevance of perception and epistemic justification. As a nonconceptualist picture of perceptual experience, it steers clear of the pitfalls of both conceptualism and stark particularism when it comes to the epistemic significance of perception. I close with a short conclusion.

\section{The Epistemic Significance of Perception and Epistemic Justification}

Perceptual experience is of central epistemic importance. It - to be exact, genuine perception ${ }^{2}-$ puts our surroundings in our view. It gives us knowledge of the world and justifies our empirical beliefs. Without perceptual awareness of the world, our epistemic situation would be much worse. The epistemic significance of perceptual experience is connected to the very concepts of knowledge and epistemic justification: For there to be more than true guesses about a subject matter, i.e. for there to 
be justified belief or knowledge, there has to be a connection between belief and truth, which in the case of empirical belief or knowledge is to say that it has to have a connection to the world. This connection is, at bottom, supplied by perception.

Let me highlight just two important epistemic roles of perception. First, perception is a starting point for appropriate reasoning about the world. For instance, that Klaus perceives that Hiltrud is snoring puts him in a position to appropriately infer that she must have been tired. Second, conscious perception allows us to show others how we came to know something perceptually and thus to vindicate our perceptual knowledge claims (Roessler forthcoming). For instance, Klaus might answer the question, "How do you know that Hiltrud is snoring?", with, "By the vibrating sound of her breathing".

To connect these claims to my discussion, it is a point in favor of any "X-first" epistemology if it respects the epistemic significance of perceptual experience and even more so if it is able to provide an account of its particular epistemic roles.

Next, epistemic justification is a positive standing of doxastic attitudes. A belief is ex post (doxastically) justified when the subject holds it for good reasons. It is merely ex ante (propositionally) justified when she possesses the same good reasons to accept the belief, but either doesn't form the belief at all or forms it for other, bad reasons. Klaus's belief that Hiltrud is sleeping is ex post justified: There is a good reason for him to form it (viz. that Hiltrud is snoring), he has the reason (thanks to his auditory perception), and he forms the belief in response to it. But if Klaus, though he hears that Hiltrud is snoring, were instead to form the belief on the basis of the horoscope's prediction that his sister would go to sleep early today, we should say that although Klaus's belief is ex ante justified, it is not ex post justified.

The ex ante/ex post distinction applies generally to responses we can give for reasons. It is applicable to any of a subject's actual or potential beliefs, but also to action, for example: When Klaus turns off the light in the bedroom for the reason that Hiltrud is sleeping, he does so for a good reason; his action is ex post justified. However, imagine that Klaus's reason to turn off the light is the bad reason that his little brother gets scared when he does so. Then his action is not ex post justified, even if ex ante justified.

The easiest way to spell out the contrast between ex ante and ex post epistemic justification is by appeal to reasons (or to evidence), as I have just done. It is noteworthy, however, that the terminology 
goes back to Goldman (1979), who doesn't appeal to reasons. He takes ex post justification to be prior, as the status a belief has when it is the output of a reliable process. From this he derives ex ante justification, the justification a proposition has for a subject if it would be suitable for her to accept it. If she could acquire the belief in her current situation by way of a reliable belief-forming process, it is ex ante justified. And if a belief isn't formed on the basis of a reliable process, even though the subject had a reliable belief forming process available to acquire it, it is ex ante, but not ex post justified.

Overall, any adequate "X-first" epistemology must cohere with and account for the shape and extent of epistemic justification. Together with the epistemic significance of perception, this gives us two explanatory desiderata which "X-first" epistemologies ought to satisfy.

\section{PIK on the Epistemic Significance of Perception and on Epistemic Justification}

Now that I have introduced the relevant explanatory desiderata, the next item on my agenda is to argue that knowledge-first views do poorly with respect to them. I will focus on two variants of knowledge-first epistemology, which I call "PIK" and "PINK". The first variant, endorsed e.g. by Byrne (2016), follows Williamson in maintaining that perceiving is a special way of knowing (PIK). According to the second variant, perception is not a kind of knowledge (PINK); rather, it provides knowledge, but without relying on epistemic reasons (Littlejohn 2017, 2018a, 2018b).

Let me turn to PIK first. That Klaus hears that Hiltrud is snoring entails that he knows that she is snoring, and even stronger, his hearing is nothing but his way of knowing that Hiltrud is snoring. Perception is partly constituted by knowledge. Perception, as a kind of knowledge, entails belief. ${ }^{3}$ In support, note that, first off, knowing that $p$ plausibly requires the subject to accept $p$ as true, i.e., to believe $p$. Second, as Glock $(2012,216)$ argues, situations in which a subject interacts successfully with her environment, i.e., situations in which she proceeds from knowing that $p$, are paralleled by situations in which the subject exercises the same epistemic capacities, but the world does not cooperate, so that she fails to know. Our natural fallback option for describing the latter subject is as (merely) believing rather than knowing that $p$. Since subjects in the good and bad cases exercise the same epistemic capacities, the subject who knows that $p$ thereby plausibly also believes that $p$. PIK is naturally wedded to conceptualism: Given that perceiving is a way of knowing and thus of believing, and given that believing constitutively involves the exercise of conceptual capacities - and that belief has a conceptual and propositional content - perceptual experience is a conceptual state with conceptual/propositional content. 
PIK is a version of knowledge-first, as it endorses the claim that knowledge is the most fundamental factive mental state. Further, perception cannot plausibly get its status as knowledge from prior epistemic normative reasons, as it is our most fundamental access to the world. Rather, subjects possess epistemic reasons and are in a position to have justified empirical beliefs in virtue of knowing perceptually. So, knowledge is more fundamental than both possessed reasons and justification.

Now how well does PIK perform regarding the explanatory desiderata? Byrne (2016) attacks broadly reasons-first positions precisely because he thinks they cannot account for the epistemic significance of perception. Ironically, it is the PIK view favored by Byrne that undermines the special epistemic significance of perceptual experience. For, according to it, a subject's perception that $p$ comes out as just another instance of knowledge that $p$. Think again of Klaus. If his hearing that Hiltrud is snoring is no more than a way of knowing that she is snoring, what is the epistemic point of the whole “technicolor phenomenology" involved in hearing (McGinn 1991: 1)? And why does he start with perceptual knowledge as distinct from generic knowledge? After all, any instance of knowledge that Hiltrud is snoring is all by itself, without perceptual forerunners and without experiential character, knowledge and thus also something from which Klaus can reason.

Let me illustrate this with the help of the imaginary superblindsighter, who comes to believe things about her surroundings immediately on the basis of subpersonal processing, while skipping the intermediary step of conscious perception. In my example, let's call Klaus's "superdeafhearer" equivalent "Blaus". His auditory system fails to output a conscious auditory experience, immediately producing in him the true belief that Hiltrud is snoring, a belief that is safe and reliably caused and so, according to the proponents of PIK, both justified and knowledge. ${ }^{4}$ (There are different ways one might fill out the details of the superdeafhearer case. For current purposes, we may allow that Blaus, though he has no conscious auditory experience of Hiltrud's snoring, has other auditory beliefs about Hiltrud's breathing, such as that it has a certain vibrating quality or a certain volume.) Given PIK, it seems that Blaus, despite lacking conscious auditory perception of Hiltrud's snoring, is epistemically speaking no worse off than Klaus. Blaus knows that his sister is snoring just as well as Klaus does, and he is able to reason on this basis just like Klaus. But this means that according to PIK, conscious perception has zero epistemic significance, as it improves Klaus's epistemic situation in no way over Blaus's.

Byrne preempts this kind of objection by arguing that Blaus is Klaus's zombie twin, so that my worry relies on the highly contentious presupposition that zombies are possible - it doesn't have to be taken seriously. However, this is incorrect. Sure, under a very coarse-grained description, Blaus and Klaus 
are functional twins: Both know that Hiltrud is snoring, both believe on that basis that she is sleeping, and so forth. But we can provide a more fine-grained description of their functioning, which uncovers many substantial differences between them. For instance, Klaus's knowledge that Hiltrud is snoring is processed within his auditory system, whereas Blaus's knowledge is processed in his central cognitive system. If Klaus comes to believe that he's hallucinating that Hiltrud is snoring, he will still be stuck with his auditory experience/belief that Hiltrud is snoring, whereas Blaus will be able to abandon his belief that Hiltrud is snoring. Given these significant functional differences between the two, my objection cannot be brushed off as just a version of the zombie worry. Rather, it highlights the fact that PIK cannot account for the special epistemic significance of perceptual experience.

But isn't PIK doing alright anyway because at least perceptual knowledge with conscious perception is epistemically no worse than perceptual knowledge without? Both get the job of providing knowledge done equally well, and this is good enough to ensure that perception is epistemically significant. I disagree that it is sufficient to show that perceptually knowing is no worse than generically knowing. For, as argued above, on our ordinary understanding, conscious perceptual experience is of special significance to our epistemic life. It plays a distinct role, which the PIK theorist cannot do justice to.

PIK also fails with respect to the explanatory desideratum concerning the shape and extent of epistemic justification. In particular, it cannot account for the ex ante justification we have for our most fundamental perceptual beliefs. On PIK, our perceptual experiences are our most fundamental perceptual beliefs. Accordingly, there has to be a fact of the matter as to whether e.g. Klaus's auditory experience/belief is ex ante justified. Take a situation in which Klaus does not yet consciously hear that Hiltrud is snoring - imagine that he has just entered the bedroom and is slightly distracted, so that he is just on the verge of becoming conscious that she is snoring. In this situation, we can legitimately raise the question: Is the auditory belief/experience ex ante justified for Klaus? It is extremely odd to ascribe such a status to an auditory experience, which doesn't seem to be a mental state that can be justified or unjustified. Ignoring these qualms, however, it has to be that the auditory belief/experience is ex ante justified for Klaus, for there is nothing wrong with his auditory perception; moreover, it can contribute to the justification of further beliefs.

The PIK theorist might deal with this issue in several ways. First, maybe a subpersonal mental state with the content that Hiltrud is snoring (or something the like) has to be processed in Klaus's auditory system for his auditory belief to be ex ante justified. But why should subpersonal processing make a difference? It seems just as well to say that, as soon as the sound of Hiltrud's snoring impinges on his 
ear drums, or as soon as he is in a position to hear that she is snoring, or as soon as she is in fact snoring, his auditory belief is ex ante justified. That is to say, subpersonal processing seems to be just as well-suited to fix the belief's ex ante status as any other causal descendant of Hiltrud's snoring. Consequently, it appears to be arbitrary whether Klaus's auditory belief is ex ante justified: It may come out as ex ante justified if we appeal to the state of his environment, but as ex ante unjustified if we appeal to his subpersonal processing. We can get out of this conundrum if we restrict providers of ex ante justification to prior awareness-involving states of Klaus. But then Klaus's auditory belief comes out as unjustified even though his auditory sense functions perfectly, for he is not aware of any relevant states prior to his hearing that Hiltrud is snoring. ${ }^{5}$

Secondly, the PIK theorist might insist that the auditory belief is ex ante justified given that it would be knowledge if Klaus were to form it. ${ }^{6}$ So, we simply need to figure out whether this counterfactual is true: "Given his current situation, if Klaus were to form the auditory belief/experience that Hiltrud is snoring, he would know perceptually that she is snoring". The advantage of this proposal is that it allows us to sidestep the issue of which antecedent state is responsible for the ex ante status of basic perceptual belief.

But how do we determine whether the relevant counterfactual is true? For instance, it seems that Klaus, when on the verge of becoming auditorily aware that Hiltrud is snoring, would know that she is snoring if he were to have the experience. But this seems no less true when the sound waves are just starting to affect Klaus's eardrums, or when he is standing in front of Hiltrud's door, just about to open it, or when he is merely heading for her room. For in these cases too, the closest possible worlds in which he has an auditory experience that Hiltrud is snoring are worlds in which he perceives that she is snoring (rather than the much more fantastic worlds in which he has an illusion or hallucinates that she is snoring). On the other hand, one might think that in the latter situations the counterfactual comes out false. For in them, if Klaus were to have an auditory experience that Hiltrud is snoring, his experience would arise in his auditory system without being caused in the right way by Hiltrud's snoring via his subpersonal processing. But if one goes down that road, it's not clear that the situation in which the information that Hiltrud is snoring is already being processed subpersonally in Klaus's auditory system is any different. Even then one might worry that the auditory experience would arise without being caused by the relevant processing - that Klaus has the experience and the relevant processing doesn't guarantee that he has the experience because of the processing. Overall, this second response on behalf of PIK fails to convince because it fails to provide firm ground for classifying basic perceptual belief as ex ante justified, assessing such belief as ex ante justified either too soon or too late. 
Thirdly, one might deny that the status is applicable to our most basic beliefs about the world. However, if perceiving is genuinely a kind of believing, how could we deny that there is a question of its ex ante justification? If, in hearing that Hiltrud is snoring, Klaus genuinely believes this, we can legitimately raise the question whether his belief would be suitable, or whether he has good reasons to believe - at least, I can think of no non-ad hoc reason why not. Think of it this way: In forming the belief that $p$, a subject jointly exercises the relevant conceptual capacities that specify the content $p$, and this is something she either does for good reasons or not. For conceptual capacities are a kind of capacities that can be exercised for good reasons. But then the question of whether the subject has good reasons so to believe can legitimately be raised. (I will get back to this point below.) Just this possibility is excluded for Klaus's so-called perceptual belief, according to the third response. Let me conclude, then, that it doesn't solve the problem.

So, PIK fails to provide a satisfying account of the ex ante justification of our most fundamental perceptual beliefs. This is because it mistakenly tries to conceive of perception as a kind of belief, which raises the issue of its ex ante justification, which leads into confusion exactly because perceptual experience is a kind of mental state to which such a status cannot be applied. Since, further, PIK cannot do justice to the special epistemic significance of perceptual experience, it should be abandoned. One way of doing this is to stick with knowledge-first while dropping the idea that perception is a kind of knowledge. I turn to such a view in the next section.

\section{PINK on the Epistemic Significance of Perception and on Epistemic Justification}

For PINK, perception is neither a kind of knowledge nor does it provide epistemic reasons. Klaus's belief that Hiltrud is sleeping is not justified or knowledge because of reasons provided by perception. Still, perception provides perceptual knowledge, which we can explain by appeal to what the subject perceives. According to Littlejohn $(2016,2017)$ and Roessler (forthcoming), such explanations appeal to the recognitional or classificatory abilities in operation in perception, which provide as their output perceptual knowledge, but whose operation doesn't rely on any epistemic reasons.

On Roessler's view, the epistemic role of perceptual experience is to provide substantial, vindicating explanations of perceptual knowledge claims. The perceptual abilities appealed to in such explanations presuppose that certain features are experienced by the subject, which he can pick out with the help of perceptual demonstratives; it is the perceptual presence of these features that enables the subject to recognize or properly classify the relevant object and thus to acquire knowledge. For instance, Klaus's conscious auditory perception manifests his capacity to tell by the sound of Hiltrud's 
breathing that she is snoring; he can pick out demonstratively the specific features of Hiltrud's breathing which enable him to tell that she is snoring; and this explains how he knows this. So his auditory perception is the source of his knowledge that Hiltrud is snoring. On this picture, perceptual knowledge is groundless - it is not based on prior reasons provided by perception, and so reasons are not fundamental to knowledge. Nonetheless, the view accords a central epistemic role to our perceptual capacities, whose employment provides our ground-level knowledge of the world as well as vindicating explanations of our knowledge. This picture of the epistemic role of perception is a natural fit with a rejection of the claim that perception has a content at all, be it conceptual or nonconceptual, and an endorsement of the view that perception is a relation between perceiver and perceived object. The latter view is associated with positions such as Campbell's (2002) relationalism or Martin's (2006) naïve realism, as well as Littlejohn's (2017) stark particularism (to be discussed below).

PINK can help itself to an intriguing account of epistemic justification, which makes knowledge fundamental to justification: All beliefs, including perceptual beliefs, are justified to the extent that they are knowledge (knowledge being the norm of belief) and to the extent that - as knowledge they can provide reasons for further responses. In Littlejohn's (2017: 42) words, "the justificatory status of a belief depends upon whether it can provide rational support by providing us with reasons". For instance, Klaus's belief that Hiltrud is snoring is justified because it can provide him with a reason to believe that she is sleeping, and thus with a reason to turn off the light and quietly leave the room. We can think of this as a forward-looking account of epistemic justification.

I find PINK much more compelling than PIK. Still, its account of the epistemic role of perception and of the shape and extent of epistemic justification is not fully satisfactory. Let's begin with the first point. On the one hand, I find Roessler's account of the epistemic significance of perception in terms of vindicating explanations of knowledge claims, which require conscious perceptual awareness of perceived features, quite compelling. But on the other hand, even this doesn't fully capture the epistemic role that perception plays for us. The superdeafhearer's problem is not only that he cannot vindicate his knowledge claims, that he can do no more than to insist that he "just knows". He has the further problem that, according to himself, his perceptual beliefs are not justified, that he apparently holds them for no reason. He finds himself with perceptual beliefs whose credentials are, from his perspective, up in the air. But his perspective is what counts in deliberation. Since he blankly finds himself with his perceptual beliefs, he has to think of himself as holding those beliefs for no reason, and so cannot appropriately use them as starting points in deliberation or reasoning. This highlights that conscious perception is needed to provide reasons for basic empirical belief. This 
problem is disconnected from whether a subject can defend her knowledge claims to others, as it is about whether she holds a belief for a reason, from her own perspective; PINK doesn't have the resources to explain this. So perception's epistemic role of providing the rational foundation of our reasoning by providing reasons for perceptual belief cannot be captured by PINK.

To accept PINK's forward-looking account of epistemic justification is already to bite that bullet: If the justification of belief is due to the reasons it provides for further responses, perception is out of the justificatory equation. But there is a further problem with the forward-looking account: It's not that belief is justified because it can provide reasons; rather, justified belief can provide reasons because it is justified. To see this, think about ways in which the normative status of an entity and its normative difference-making powers may relate.

(1) Something has a certain normative status because it has the power to make a difference with respect to a distinct normative status. Example: An agent is legally accountable for her actions because she has the power to perform actions that are morally praise- or blameworthy. (2) Something has the power to make a normative difference because it has a normative status of the same kind. Example: An employment contract has the power to make it illegal for an employer not to pay her employee because it is a legal employment contract. This all seems perfectly fine. What I find unbelievable is that something should itself acquire a certain status because it makes a normative difference of the same kind to something else. Just this would have to be the case for beliefs to be epistemically justified because they provide epistemic reasons. Let me explain.

That a belief is epistemically justified because it provides the believer with moral reasons to act, for instance, is not problematic, as when Klaus's justified belief that Hiltrud is sleeping provides him with a moral reason to turn off the light and leave the room. So, this might be a type (1) case, and Klaus's belief might be epistemically justified because it provides a reason of a moral kind. What causes trouble, however, is the claim that a belief may be epistemically justified because it can provide epistemic reasons, as when Klaus's belief that Hiltrud is snoring is allegedly epistemically justified because it can provide him with an epistemic reason to believe that she is sleeping. Compare: The premises of a valid argument can support its conclusion just in case they are independently supported by argument. But what explains what? It is certainly not true that the premises are rationally acceptable because they can support the conclusion. Rather, they can support the conclusion, or render it rationally acceptable, because they are independently supported by argument, or rationally acceptable. By analogy, a belief can provide epistemic reasons for further beliefs, and thus contributes 
to their positive epistemic status, because it is epistemically justified. So, the epistemic justification of belief plausibly falls under type (2).

Proponents of PINK might respond that any justified belief can in principle provide reasons for nonepistemic responses, so there is no problem for the forward-looking account. I am not convinced, as there seems to be plenty of room for epistemically justified beliefs that have zero practical, moral, or other relevance, which therefore cannot provide an agent with any non-epistemic reasons. ${ }^{7}$ Admittedly, it may still be that, as mentioned above, beliefs are justified because they are knowledge. However, either account of epistemic justification will be completely different than (what I take to be) PINK's account of the justification of any of the other responses. For these, the view is that they are justified because supported by the subject's reasons. But for belief, justification is due to its reasons-providing powers or to its own status as knowledge. This makes for an inelegant, disunified picture of the unitary phenomenon of justification. ${ }^{8}$

Overall then, while PINK has better explanatory resources than PIK, it fails to give a fully satisfying account of both the epistemic significance of perceptual experience and of epistemic justification.

\section{Reasons-First on the Epistemic Significance of Perception and on Epistemic Justification}

So far, I have tried to show that neither variant of the knowledge-first view, PIK or PINK, fully satisfies the two explanatory desiderata under discussion. The next step in my argument is to show that reasons-first does a much better job.

As briefly sketched above, on my picture, epistemic justification and knowledge arise from possessed epistemic reasons. The relevant reasons are normative epistemic reasons, facts that epistemically favor adopting certain doxastic attitudes, including belief, disbelief, and suspension of judgment. ${ }^{9}$ Think of knowledge and justified belief as belief for a reason, which requires the believer to manifest epistemic rational capacities to connect with and to be attuned to reality, in particular capacities to form the belief that the subject's epistemic reasons favor for these reasons. A subject justifiably believes that $p$ just in case, one, the epistemic reasons she possesses all things considered favor her accepting $p$ and, two, in believing that $p$, she manifests her epistemic rational capacities. Knowledge is belief that is true because it is a competent response to possessed sufficient reasons: A subject knows that $p$ just in case, one, her reasons sufficiently and all things considered favor her believing that $p$ and, two, her belief that $p$ is both a manifestation of her epistemic rational capacity and true because it is such a manifestation. 
By justifiably believing or knowing that $p$, the subject possesses that $p$ as a reason which she can use in further reasoning, and correspondingly, we can think of epistemic rational capacities as capacities to possess epistemic reasons. In Schmidt (2019), I distinguish two kinds of manifestations of epistemic rational capacities - that is, two ways of possessing epistemic reasons -, justified beliefs on the one hand and presentational attitudes not in need of justification (or PANINIs) on the other. PANINIs are basic presentational attitudes like memory, rational intuition, or perception (which is my focus here), for which it doesn't make sense to question their justificatory status.

On my view, perception is not a kind of knowledge, nor is it a kind of belief, as it is not the manifestation of a capacity to adopt an attitude in the light of a possessed normative reason, but rather a response to unpossessed epistemic reasons. For we cannot perceive for a reason, nor is it something subjects do in the light of possessed reasons. We aren't persuaded by the good reasons we have to perceive something, we just do, as a ground-level response to our environments. ${ }^{1011}$ Still, the account highlights that knowledge and perception have important structural commonalities: Both are true or correct because they are manifestations of epistemic rational capacities to be attuned to the world, and to have these capacities is to be sensitive to epistemic reasons. Perception, like belief, is geared towards attaining knowledge; it is how epistemic reasons for empirical belief are brought into the subject's view in the first place.

One way to make sense of the differences between perceptual experience and belief is by appeal to state nonconceptualism about perceptual experience (Schmidt 2015): Perceptual experience is nonconceptual - it is possible to perceive that $p$ without exercising the concepts needed to specify the content that $p$. By contrast, belief is conceptual, for in order to believe that $p$, the subject has to exercise the concepts needed to specify the content that $p$. On this view, belief, but not perceptual experience, is constituted by a joint exercise of conceptual capacities. Plausibly, conceptual capacities are the kind of capacities we can consciously employ for good reasons, and consequently, belief is a kind of state that the subject can adopt or revise in the light of her reasons; in this sense, its conceptual nature puts it under the subject's rational control and thus makes it suitable for us to question its justification. Since perception constitutively involves the activation not of conceptual, but rather of perceptual-discriminatory capacities, which are simply triggered in suitable circumstances as a manifestation of the subject's ground-level sensitivity to the world, it cannot be adopted or revised in the light of the subject's reasons. In this way, our lack of rational control over what we perceive can be explained by appeal to the nonconceptual nature of perception. And this in turn explains why it is 
inappropriate to ascribe to perception the epistemic status of being justified or unjustified, but also why perception is ideally suited to be a starting point of our reasoning about the world.

We can form justified beliefs and come to know in response to epistemic reasons we possess thanks to employing perceptual capacities that bring our environment into view. It is essential for perception to play this role that it both involves conscious awareness of the subject's environment and that it be unassessable as justified or unjustified. Let me illustrate this again with the case of Blaus. As argued above, from Blaus's perspective, the credentials of his auditory belief that Hiltrud is snoring are up in the air; he cannot be sure whether by believing he possesses a reason he can use in further deliberation or whether this is just some random belief he got stuck with. For belief is a kind of presentational attitude with respect to which the question of justification can legitimately be raised; it is justified only when it is a response to a normative reason the subject already possesses. Since Blaus's subpersonal processing leading up to his auditory belief is not conscious, it is not a way for him of possessing a reason in support of the belief. So when Blaus comes to believe that Hiltrud is snoring, his belief isn't justified, for it is not a response to a possessed reason.

This illustrates that neither unconscious subpersonal states nor belief are able to fill the role of a starting point of deliberation. This is why conscious perception is of central epistemic significance as a conscious state, it can provide the subject with reasons; and as a state that is not assessable as justified or unjustified, it can do so without forcing her to first worry about its justification.

With respect to accounting for our ability to provide vindicating explanations of perceptual knowledge, I am happy to follow Roessler's lead. Reasons-first is compatible with appealing to perceptual skills in vindicating explanations of knowledge, for we can think of such skills as part and parcel of the perceiver's rational capacities to pick up on her environment.

Littlejohn (2017), as a proponent of PINK, objects that perception is contentless, relating the perceiver to nothing but particulars, so that it cannot provide her with reasons in the form of pre-existing facts, given that facts always involve general elements. When perceivers exercise their capacities to recognize or categorize the bare particulars they are confronted with perceptually, they immediately end up with beliefs, not perceptual experiences; in belief, partly general contents are generated for the first time. Call Littlejohn's view 'stark particularism'. Part of his motivation is that there is no explanatory advantage to pushing these contents, including their general elements, back into perceptual experience. 
But this is not true. As I argue elsewhere, the exact metaphysical nature of (the content of) perceptual experience is in the end a pragmatic issue, i.e. an issue of which metaphysical presuppositions we need to make so that perception can best play all the theoretical roles we need it to play (Schmidt 2015, Unpublished Manuscript). Theories which ascribe facts as perceptual contents (which, on my nonconceptualist picture, are not true Fregean propositions, but obtaining states of affairs including general elements), or theories which say that perception relates perceivers to such facts, can easily account for the existence of normative reasons; for how these come into the perceivers possession; and for how perceivers can believe, act, etc. in response to them. Littlejohn's stark particularist account of perception, by contrast, raises worries as to how the world can do anything to favor certain responses. How could an entirely particular agglomeration normatively speak in favor of a certain response? In virtue of what might the application of a certain set of classifications or recognitional capacities, rather than any other, to this agglomeration be correct? How could subjects acquire capacities to classify and to correctly to respond to such agglomerations? Reasons-first epistemology, with its assumption that perception has a content, elegantly bypasses such worries. It therefore has an advantage over stark particularism. Overall, my nonconceptualist version of reasons-first steers an ideal middle path between conceptualism/PIK (which, by taking perception to be just another kind of conceptual belief, struggles to explain its special role in our reasoning) and stark particularism/PINK (which, by denying that perception has any kind of content, struggles to account for normative reasons and for our capacities to pick up on and respond to them).

Finally, let me briefly address how reasons-first accounts for the extent and shape of epistemic justification. Any response that a subject can give for good reasons is ex ante justified to the extent that it is favored, all things considered, by the subject's normative reasons. Reasons-first thus provides a unified account of this normative status, no matter whether we're looking at action, belief, or other responses, and no matter whether we are dealing with basic perceptual beliefs or beliefs farther up the chain. Perceptual beliefs are ex ante justified just in case they are favored all things considered in the light of epistemic reasons possessed by the subject by perceiving. Since perceiving is not believing, but a distinct nonconceptual kind of state, we're not stuck with thinking of perception as justified or unjustified. Finally, since reasons-first is not a forward-looking account of epistemic justification, the view can ascribe justification even to beliefs that could never provide reasons for non-epistemic responses.

\section{Results}

This concludes my argument for reasons-first epistemology. "X-first" epistemologies are positions concerning the relative explanatory fundamentality of certain epistemic phenomena. The natural way 
to compare them is to investigate how well the relevant phenomena are indeed explained under the assumption that $\mathrm{X}$ is first. I have done this here by comparing how well reasons-first and knowledgefirst are able to explain both the specific ways in which perception is central to our epistemic lives, and the shape and extent of epistemic justification.

My findings were that equating perception with a kind of knowledge (PIK) makes it extremely difficult for knowledge-first to accord any epistemic role to perception, as illustrated by superblindsighter cases. Further, the view struggles to give a tenable account of the ex ante justification of basic perceptual belief. Rejecting this equation (PINK) improves the explanatory performance of knowledge-first; but even this view cannot account for the epistemic role of conscious perception as a starting point of deliberation. Moreover, the forward-looking account of epistemic justification I discussed is problematic, for it implausibly makes epistemic justification hinge on whether a belief can provide reasons for further non-epistemic responses.

By comparison, reasons-first is an explanatory over-achiever: It can account for all facets of the role of conscious perception in our epistemic lives, and it properly delineates the shape and extent of epistemic justification. Coming from a slightly different angle, nonconceptualist reasons-first best captures the epistemic features of perception by taking up a middle ground between conceptualist PIK, which implausibly accords perception the exact same epistemic role as any other type of knowledge; and particularist PINK, which problematically denies it any reason-providing role. It is its explanatory merits, then, that speak in favor of reasons-first.

\section{Acknowledgements}

I would like to thank Alex Byrne, Johannes Roessler, and the audience at the conference Norms and Reasons in Zürich (2018) for helpful comments and discussion.

\section{References}

Byrne, A. (2016) 'The Epistemic Significance of Experience', Philosophical Studies, 173 (4), $947-$ 967.

Campbell, J. (2002) Reference and Consciousness. Oxford: Oxford University Press.

Glock, H. (2012) 'Thought, Judgment and Perception', Grazer Philosophische Studien, 86, 207221.

Goldman, A. (1979) 'What is Justified Belief?', in Pappas, G. (ed.) Justification and Knowledge. Dordrecht: Reidel, 1-24. 
Littlejohn, C. (2016) 'Pritchard's Reasons', Journal of Philosophical Research, 41, 201-219.

Littlejohn, C. (2017) 'How and Why Knowledge is First', in Carter, A., Gordon, E. and Jarvis, B. (eds.) Knowledge-First Epistemology. Oxford: Oxford University Press, 19-45.

Littlejohn, C. (2018a) 'Reasons and Theoretical Rationality', in Star, D. (ed.) The Oxford Handbook of Reasons and Normativity. Oxford: Oxford University Press, 529-551.

Littlejohn, C. (2018b) 'The Right in the Good: A Defense of Teleological Non-Consequentialism in Epistemology', in Ahlstrom-Vij, K. and Dunn, J. (eds.) Epistemic Consequentialism. Oxford:

Oxford University Press, 23-47.

Martin, M. G. F. (2004) 'The Limits of Self-Awareness', Philosophical Studies, 120, 37-89.

McGinn, C. (1991) The Problem of Consciousness. Oxford: Basil Blackwell.

Roessler, J. (forthcoming) 'The Manifest and the Philosophical Image of Perceptual Knowledge', in Stadler, F. and Limbeck-Lilienau, C. (eds.), The Philosophy of Perception and Observation

(Proceedings of the 40th International Wittgenstein Symposium). Berlin: De Gruyter.

Schmidt, E. (2015) Modest Nonconceptualism: Epistemology, Phenomenology, and Content. Cham: Springer.

Schmidt, E. (2019) 'Possessing Epistemic Reasons: The Role of Rational Capacities', Philosophical Studies, 176 (2), 483-501.

Schmidt, E. (2018) 'Normative Reasons for Mentalism’, in Kyriacou, C. and McKenna, R. (eds.)

Metaepistemology: Realism and Anti-Realism. London: Palgrave Macmillan, 97-120.

Schmidt, E. (Unpublished Manuscript) Can We Do Without Content Pragmatism?

Siegel, S. (2012) 'Cognitive Penetrability and Perceptual Justification’, Noûs, 46 (2), 201-222.

Siegel, S. (2013) 'The Epistemic Impact of the Etiology of Experience', Philosophical Studies, 162 (3), 697-722.

Turri, J. (2009) 'The Ontology of Epistemic Reasons', Nô̂s, 43 (3), 490-512.

Williamson, T. (2000) Knowledge and Its Limits. Oxford: Oxford University Press.

Williamson, T. (2018) 'Knowledge, Action, and the Factive Turn', in Mitova, V. (ed.) The Factive

Turn in Epistemology. Cambridge: Cambridge University Press, 125-141.

\footnotetext{
${ }^{1}$ A note of caution: The scope of my argument is by necessity limited, for even if successful, it throws a bad light only on the specific variants of knowledge-first discussed. But there may be other ways in which knowledge may be taken as explanatorily fundamental to reasons, which I cannot here address. ${ }^{2}$ I follow established usage here, taking perception to be our successful sensory contact with the world, and perceptual experience the mental state that is in common between success cases and cases of failed perception such as hallucination.

${ }^{3}$ As endorsed by Williamson (2018: 132) and emphasized by Byrne's (2016: 962-963) doxastic view, "belief [is] a constitutive component of experience, as it is a constitutive component of knowledge".

${ }^{4}$ Byrne endorses reliabilism and Williamson a safety condition on knowledge.
} 
5 The same problem can be raised for Goldman's reliabilist (1979) understanding of ex ante justification. He holds that the subject's ex ante justification is determined by her cognitive state at the time, but it is not clear what all goes into this state, nor why it should be the cognitive state rather than the state of her environment that matters. Again, whether we can ascribe the status becomes arbitrary.

${ }^{6}$ I thank Christoph Pfisterer for this suggestion.

${ }^{7}$ Further trouble for the forward-looking account is in the offing from suspension of judgment: Suspending on $p$ may provide me with reason to suspend on $q$ as well (cf. Turri 2009), but rarely seems to give me practical or moral reason to do anything.

${ }^{8}$ This is part of the reason why in my discussion of PIK, I assumed that this view doesn't come with an account of justification in terms of meeting the knowledge norm. The other part of my reason was that it is an advantage of PIK that it allows for perception to contribute to the justification of belief by providing reasons; an advantage which the knowledge-norm account of justification would eliminate. Thanks to Giada Fratantonio for pressing me on this.

${ }^{9}$ See Schmidt (2018) for the nuances of my position on epistemic reasons.

${ }^{10}$ The same holds for the other PANINIs.

${ }^{11}$ Subjects can put themselves in certain perceptual positions for good reasons - for instance, I can direct my gaze in a certain direction to better see what is going on there. There is also room for epistemically pernicious influences on perception by way of cognitive penetration or biases (cf. Siegel 2012, 2013), which in my view prevent the manifestation of epistemic rational capacities. 